\title{
Journal of

\section{The Two Formyl Peptide Receptors Differently Regulate GPR84-Mediated Neutrophil NADPH Oxidase Activity}

\author{
Jonas Mårtensson ${ }^{\mathrm{a}}$ Martina Sundqvist ${ }^{\mathrm{a}} \quad$ Asmita Manandhar $^{\mathrm{b}}$ \\ Loukas Leremias $^{b}$ Linjie Zhang ${ }^{c, d}$ Trond Ulven $^{b}$ Xin Xie $^{c, d}$ Lena Björkman ${ }^{a}$ \\ Huamei Forsman ${ }^{\text {a }}$ \\ aDepartment of Rheumatology and Inflammation Research, University of Gothenburg, Gothenburg, Sweden; \\ ${ }^{b}$ Department of Drug Design and Pharmacology, University of Copenhagen, Copenhagen, Denmark; 'CAS Key \\ Laboratory of Receptor Research, The National Center for Drug Screening, Shanghai Institute of Materia Medica,

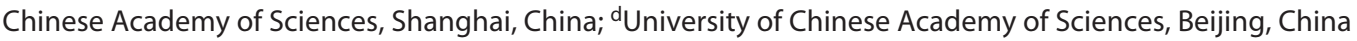

\section{Keywords}

Neutrophils $\cdot G$ protein-coupled receptors $\cdot$ Cross-talk . Nicotine adenine dinucleotide phosphate oxidase

\begin{abstract}
Neutrophils express the two formyl peptide receptors (FPR1 and FPR2) and the medium-chain fatty acid receptor GPR84. The FPRs are known to define a hierarchy among neutrophil $G$ protein-coupled receptors (GPCRs), that is, the activated FPRs can either suppress or amplify GPCR responses. In this study, we investigated the position of GPR84 in the FPR-defined hierarchy regarding the activation of neutrophil nicotine adenine dinucleotide phosphate (NADPH) oxidase, an enzyme system designed to generate reactive oxygen species (ROS), which are important regulators in cell signaling and immune regulation. When resting neutrophils were activated by GPR84 agonists, a modest ROS release was induced. However, vast amounts of ROS were induced by these GPR84 agonists in FPR2-desensitized neutrophils, and the response was inhibited not only by a GPR84-specific antagonist but also by an FPR2-specific antagonist. This sug-
\end{abstract}

gests that the amplified GPR84 agonist response is achieved through a reactivation of desensitized FPR2s. In addition, the GPR84-mediated FPR2 reactivation was independent of $\beta$-arrestin recruitment and sensitive to a protein phosphatase inhibitor. In contrast to FPR2-desensitized cells, FPR1 desensitization primarily resulted in a suppressed GPR84 agonist-induced ROS response, indicating a receptor hierarchical desensitization of GPR84 by FPR1-generated signals. In summary, our data show that the two FPRs in human neutrophils control the NADPH oxidase activity with concomitant ROS production by communicating with GPR84 through different mechanisms. While FPR1 desensitizes GPR84 and by that suppresses the release of ROS induced by GPR84 agonists, amplified ROS release is achieved by GPR84 agonists through reactivation of the desensitized FPR2.

\section{The Author(s)}

Published by S. Karger AG, Basel

Jonas Mårtensson and Martina Sundqvist as well as Lena Björkman, and Huamei Forsman, contributed equally to the work.
C 2021 The Author(s)

Published by S. Karger AG, Basel

This is an Open Access article licensed under the Creative Commons Attribution-NonCommercial-4.0 International License (CC BY-NC) (http://www.karger.com/Services/OpenAccessLicense), applicable to the online version of the article only. Usage and distribution for commercial purposes requires written permission.
Correspondence to:

Huamei Forsman, huamei.forsman@ rheuma.gu.se 


\section{Introduction}

Neutrophils, major effector cells in innate immunity, constitute a vital part of the defense against invading microbes and other protective inflammatory processes but can also mount pathological actions leading to tissue damage $[1,2]$. The multifaceted functions of neutrophils, including directional migration, secretion of granule constituents, and activation of the reactive oxygen species (ROS)-generating nicotine adenine dinucleotide phosphate $(\mathrm{NADPH})$ oxidase, are regulated and fine-tuned by different receptors belonging to the family of $G$ proteincoupled receptors (GPCRs) [3, 4]. Neutrophils express a number of GPCRs of importance for initiation as well as resolution of inflammation, including the two formyl peptide recognizing receptors (FPR1 and FPR2), receptors that recognize platelet-activating factor (platelet-activating factor receptor [PAFR]), interleukin 8(CXCR1/2), and free fatty acids (GPR84, FFAR2) $[3,5,6]$. ROS generated by the NADPH oxidase play roles not only in bacterial killing and tissue destruction activities but also in cell signaling and immune regulation [7-10]. Thus, it is of utmost importance that activation of the oxidase is a wellregulated process; an efficient inflammatory response should be achieved without causing any unnecessary collateral tissue damage.

The neutrophil response triggered by GPCRs relies not only on the specific agonists that activate their respective receptor but also on a complex receptor downstream signaling network and different hierarchical receptor crosstalk mechanisms that regulate receptor activities and fine-tune the functions of neutrophils [6]. The complexity can be illustrated by a defined position of receptor hierarchical cross-talk between FPRs and other GPCRs. For example, on the one hand, signals generated downstream of the FPRs heterologously desensitize CXCR1/2 and totally abrogate IL-8-induced neutrophil functions [1114]. On the other hand, FPR agonists amplify the response induced by PAF and ATP through a receptor cross-talk mechanism with the PAFR and the $\mathrm{P}_{2} \mathrm{Y}_{2} \mathrm{R}$ (receptor for ATP), respectively [15-17].

GPR84 has been suggested to sense the mediumchain fatty acids such as lauric acid and capric acid that are available through food intake [18]. Based on the facts that GPR84 recognizes medium-chain fatty acids and is highly expressed by neutrophils, this receptor has been suggested to constitute a molecular link between metabolism and inflammation [18-20]. The precise activation mechanism(s) and the physiological role of GPR84 remain largely unknown, but the identification of several potent GPR84-selective agonists as well as antagonists over the last years has greatly increased our understanding of this receptor (see the two recent reviews $[21,22]$ ). The availability of these powerful molecular tool compounds makes it possible to perform mechanistic studies focusing on GPR84 signaling and regulation.

In this study, we have used several newly developed GPR84 targeting molecular tool compounds to determine the regulatory effects of FPRs on GPR84-triggered activation of neutrophils. The data obtained clearly show that FPR1 and FPR2 affect GPR84-mediated neutrophil ROS production. Our results add new knowledge regarding the complexity of neutrophil GPCR communication hierarchy demonstrated by that the two very closely related FPRs regulate the function of GPR84 differently. Whereas FPR1 primarily suppressed the GPR84-induced ROS production, a suppression suggested to be achieved through heterologous GPR84 desensitization by FPR1generated signals, FPR2 augmented the response induced by GPR84-specific agonists. The basis for the increased GPR84-mediated ROS production in FPR2-desensitized cells is disclosed to involve a novel receptor cross-talk mechanism by which signals generated by GPR 84 reactivate desensitized FPR2.

\section{Materials and Methods}

\section{Chemicals}

Dextran and Ficoll-Paque were obtained from GE-Healthcare Bio-Sciences (Waukesha, WI, USA). Horseradish peroxidase was obtained from Roche Diagnostics (Mannheim, Germany). Isoluminol, dimethyl sulfoxide, and formylated tripeptide $N$-formylMet-Leu-Phe (fMLF) were obtained from Sigma Chemical Co. (St. Louis, MO, USA). Cyclosporine $\mathrm{H}$ was kindly provided by Novartis Pharma (Basel, Switzerland). FPR2 pepducin F2Pal $10, \mathrm{PIP}_{2^{-}}$ binding peptide PBP10, hexapeptide WKYMVM, mitochondrial cryptic peptide (mitocryptide) NADH dehydrogenase subunit 4, and formylated tetrapeptide $N$-formyl-Met-Ile-Phe-Leu (fMIFL) were synthesized and HPLC-purified by TAG Copenhagen A/S (Copenhagen, Denmark). Calyculin A was purchased from Nordic Biosite (Täby, Sweden), and the Src family kinase inhibitor PP2 was from Calbiochem (La Jolla, CA, USA). PAF was obtained from Avanti Polar Lipids (Alabaster, AL, USA), and ZQ16 (2-(hexylthio)pyrimidine-4,6-diol) was from Tocris Bioscience (Bristol, UK). The earlier described GPR84-specific agonists Cpd51 (6-nonylpyridine-2,4-diol) and DL175 were synthesized as described $[23,24]$. The antagonist GLPG1205 was kindly provided by Galapagos NV (Mechelen, Belgium). All peptides were dissolved in dimethyl sulfoxide and stored at $-80^{\circ} \mathrm{C}$ until use. Subsequent dilutions of all peptides were made in Krebs-Ringer phosphate buffer (KRG, pH 7.3; $120 \mathrm{mM} \mathrm{NaCl}, 5 \mathrm{mM} \mathrm{KCl}, 1.7$ mM KH${ }_{2} \mathrm{PO}_{4}, 8.3 \mathrm{mM}$ $\mathrm{NaH}_{2} \mathrm{PO}_{4}$, and $10 \mathrm{mM}$ glucose) supplemented with $\mathrm{Ca}^{2+}(1 \mathrm{mM})$ and $\mathrm{Mg}^{2+}(1.5 \mathrm{mM})$. 


\section{Isolation of Human Neutrophils}

Human peripheral blood neutrophils were isolated from buffy coats from healthy blood donors using dextran sedimentation and Ficoll-Paque gradient centrifugation as described previously [25, 26]. The remaining erythrocytes were disrupted by hypotonic lysis, and the neutrophils were washed twice and resuspended in KRG and stored on melting ice until use. This isolation process permits cells to be purified with minimal granule mobilization.

\section{Neutrophil NADPH Oxidase Activity}

The NADPH oxidase activity was determined using isoluminol-enhanced chemiluminescence (CL) that measures the superoxide release [27]. The CL activity was measured in a 6-channel Biolumat LB 9505 (Berthold Co., Wildbad, Germany) using disposable $4-\mathrm{mL}$ polypropylene tubes with a $900-\mathrm{mL}$ reaction mixture containing $10^{5}$ neutrophils, isoluminol $\left(2 \times 10^{-5} \mathrm{M}\right)$, and horseradish peroxidase ( 2 Units $/ \mathrm{mL}$ ). The tubes were equilibrated in the Biolumat for $5 \mathrm{~min}$ at $37^{\circ} \mathrm{C}$, after which the stimulus $(100$ $\mu \mathrm{L}$ ) was added (or two different agonists were added simultaneously for some experiments), and the light emission was recorded continuously over time. The light emission/superoxide anion production is expressed as mega counts per minute (Mcpm).

When receptor-desensitized cells were studied, naïve (non-desensitized) cells were first stimulated with a receptor-specific agonist, and when the release of superoxide had declined, a second stimulation was performed. When experiments were performed with antagonists during reactivation, these were added to the neutrophils in the CL reaction mixture 1 min before the second stimulation. For F2Pal 10 "washout" experiments, neutrophils $\left(10^{7} / \mathrm{mL}\right)$ were first activated/desensitized with $\mathrm{F} 2 \mathrm{Pal}_{10}(500 \mathrm{nM})$ at $37^{\circ} \mathrm{C}$ for 5 min to allow FPR 2 desensitization. Thereafter, $10 \mu \mathrm{L}$ suspension containing FPR2-desensitized cells was transferred to pre-warmed $\mathrm{CL}$ reaction mixture with $500 \mathrm{nM} \mathrm{F}^{\mathrm{Pal}_{10}}$ (to keep the $\mathrm{F}_{2} \mathrm{Pal}_{10}$ concentration constant during reactivation) or KRG (to obtain a $100 \times$ diluted $\mathrm{F} 2 \mathrm{Pal}_{10}$ concentration during reactivation), followed by reactivation with the GPR84 agonist. For ROS-mediated inactivation of FPR agonist experiments, neutrophils $\left(2-20 \times 10^{5} / \mathrm{mL}\right)$ received FPR agonist fMLF $(1 \mu \mathrm{M})$ or WKYMVM $(1 \mu \mathrm{M})$ at low temperature to allow the FPRs to become desensitized without ROS production. The FPR-desensitized cells were warmed up at $37^{\circ} \mathrm{C}$ for $5 \mathrm{~min}$, followed by stimulation with GPR84 agonist to allow receptor cross-talk-induced ROS production and FPR agonist oxidation. The supernatants were collected, and the remaining activity of the FPR agonists after ROS oxidation was determined through their potential to trigger ROS release from a new batch of neutrophils.

\section{GPR84-Mediated Cyclic Adenosine Monophosphate Assay}

HEK293 cells stably expressing GPR84 developed in our laboratory previously [28] were harvested and resuspended in DMEM containing $500 \mu \mathrm{M}$ IBMX (an inhibitor of cyclic nucleotide phosphodiesterases) at a density of $4 \times 10^{5}$ cells $/ \mathrm{mL}$. Cells were then plated onto a 384 -well assay plate at 2,000 cells $/ 5 \mu \mathrm{L} /$ well. Another $5 \mu \mathrm{L}$ buffer containing compounds at various concentrations was added to the cells. After incubation at room temperature for 30 min, 5- $\mu \mathrm{L}$ DMEM containing $15 \mu \mathrm{M}$ forskolin (to increase the level of cyclic adenosine monophosphate [cAMP], so the subsequent lowering of the cAMP level due to Gai activation can be observed) was added, and the incubation was continued for another $30 \mathrm{~min}$. Intracellular cAMP measurement was carried with a LANCE Ultra
cAMP kit (Cat No: TRF0264; PerkinElmer, Waltham, MA, USA) using an EnVision multiplate reader (PerkinElmer, Waltham, MA, USA) according to the manufacturer's instructions. This assay is a homogeneous time-resolved fluorescence resonance energy transfer immunoassay, based on the competition between the europium (Eu) chelate-labeled cAMP tracer and cellular cAMP for binding sites on CAMP-specific monoclonal antibodies. A decrease in intracellular cAMP results in higher fluorescence resonance energy transfer signal.

\section{GPR84-Mediated $\beta$-Arrestin2 Recruitment}

The recruitment of $\beta$-arrestin2 to GPR84 was measured using the Promega NanoBiT Protein-Protein Interaction System [29]. In brief, HEK293 cells $\left(2 \times 10^{6}\right)$ were transfected with plasmids encoding SmBit- $\beta$-arrestin2 $(1 \mu \mathrm{g})$ and GPR84-LgBit $(1 \mu \mathrm{g})$ by electroporation with a Scientz-2C electroporation apparatus (Scientz Biotech, Ningbo, China). The cells were seeded at $4 \times 10^{5}$ cells/well on 96 -well plates and incubated at $37^{\circ} \mathrm{C}$ with $5 \% \mathrm{CO}_{2}$. Twenty-four hours later, the cell media was replaced with $40 \mu \mathrm{L}$ fresh culture medium without FBS. Thereafter, $10 \mu \mathrm{L}$ Nano-Glo Live Cell reagent was added according to the manufacturer's protocol (Cat No: N2011; Promega, Madison, WI, USA), and the cells were incubated at $37^{\circ} \mathrm{C}$ with $5 \% \mathrm{CO}_{2}$ for 5 min before another $25 \mu \mathrm{L}$ culture media with various concentrations of compounds was added to the cells. After incubation at room temperature for $15 \mathrm{~min}$, bioluminescence was measured with an EnVision multiplate reader 2104 (PerkinElmer, Waltham, MA, USA).

\section{Data Analysis}

Data processing and analysis was performed using GraphPad Prism 8.0.0 (GraphPad Software, San Diego, CA, USA). Curve fitting was performed by nonlinear regression using the sigmoidal dose-response equation (variable-slope). For statistical analysis, either a paired Student's $t$ test or a repeated measures one-way ANOVA followed by Dunnett's multiple comparison test was used as indicated in the figure legends. All statistical analyses were performed on raw data values, and statistically significant differences are indicated by ${ }^{*} p<0.05$ or ${ }^{* *} p<0.01$.

\section{Results}

\section{Naïve Neutrophils Activated by GPR84-Specific Agonists Release ROS}

Activation of neutrophils by several GPCR agonists triggers an assembly of the NADPH oxidase and a release of ROS [3]. Accordingly, when naïve human neutrophils were stimulated with the two GPR84-specific agonists ZQ16 and its structural analog Cpd51 ([23]; structures shown in Fig. 1a, b), the NADPH oxidase was activated to produce ROS (Fig. 1c). The poor ROS response mediated through GPR84 is in line with our earlier results [20]. The ROS production profile mediated by GPR 84 agonists was very similar to that induced by the FPR2-specific agonist pepducin $\mathrm{F}_{2} \mathrm{Pal}_{10}$, that is, the response was induced rapidly upon agonist stimulation and was terminated within 
Fig. 1. Chemical structures of GPR84 agonists and their ability to activate the neutrophil NADPH oxidase. Chemical structures of the GPR84 agonists ZQ16 (a) and the ZQ16 structural related analog Cpd51 (b). c, d Naïve neutrophils were stimulated with $\mathrm{F}_{2} \mathrm{Pal}_{10}(500 \mathrm{nM}), \mathrm{ZQ} 16(1 \mu \mathrm{M})$, or Cpd51 (1 nM), after which the release of superoxide was measured continuously over time. c One representative trace of the superoxide anion release. $\mathbf{d}$ A summary of the peak superoxide anion production presented in bar graph as \% of the $\mathrm{F}_{2} \mathrm{Pal}_{10}$ response (mean + SEM, $n=4)$. A repeated measures one-way ANOVA followed by Dunnett's multiple comparison test was used to compare the GPR84-induced activation to the $\mathrm{F} 2 \mathrm{Pal}_{10}$ response. $\mathrm{NADPH}$, nicotine adenine dinucleotide phosphate.

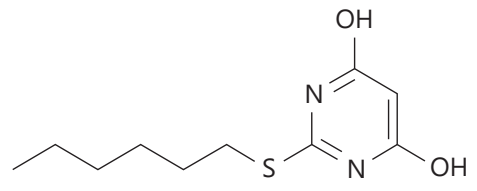

a

ZQ16

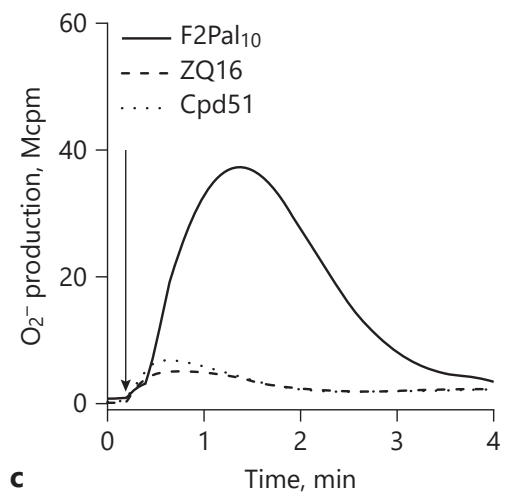

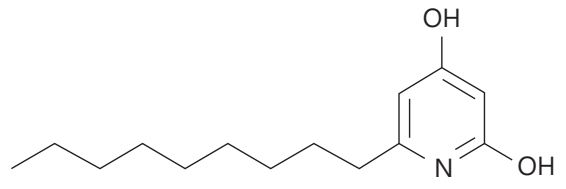

b

Cpd51

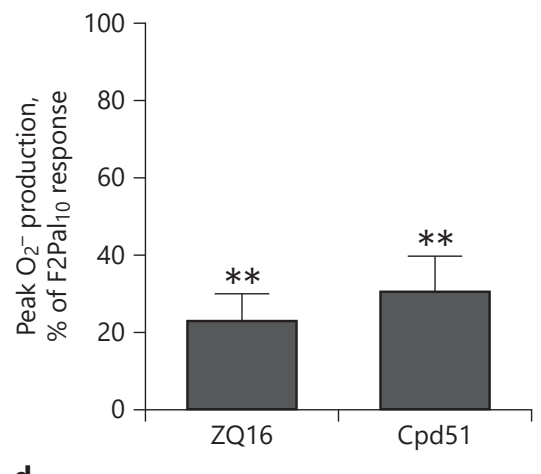

3 min after initiation (Fig. 1c). However, the maximal GPR84 agonist-induced ROS production from naïve neutrophils was low in comparison to that induced by a standard concentration (500 nM) of F2Pal ${ }_{10}$ (Fig. 1c, d). These data show that both FPR2 and GPR84 agonists trigger an activation of the neutrophil NADPH oxidase, but that the magnitude of the GPR84-induced ROS response is less pronounced as compared to the response induced by the FPR agonists.

\section{The GPR84-Mediated ROS Release Is Largely}

\section{Amplified in FPR2-Desensitized Neutrophils}

As shown in Figure 1c, ROS production following activation of FPR 2 is rapidly terminated. When the activity has returned to basal levels, these neutrophils are nonresponsive (desensitized) to additional activation with same agonist (shown with $\mathrm{F}_{2} \mathrm{Pal}_{10}$ in Fig. 2a) as well as other FPR2 selective agonists [30]. Of note, FPR2-desensitized neutrophils have ability to regain their responsiveness to FPR2 agonists if the agonist is removed, as demonstrated in our previous study [31]. However, the level of ROS released from F2Pal ${ }_{10}$-desensitized neutrophils when triggered by ZQ16 was significantly increased when compared to the ZQ16 response from naïve neutrophils (Fig. 2a, b). The level of the ZQ16-induced ROS production in FPR2-desensitized neutrophils was dependent on the $\mathrm{F} 2 \mathrm{Pal}_{10}$ concentration used to desensitize the receptor, reaching a maximum level with $\sim 250 \mathrm{nM}$ F2Pal ${ }_{10}$ (Fig. 2b). The enhanced level of ZQ16-induced ROS production in FPR2-desensitized neutrophils was not restricted to the use of $\mathrm{F} 2 \mathrm{Pal}_{10}$ as the desensitizing agonist, as similar amplifications were also obtained when FPR2 was desensitized with the FPR2 agonists mitochondrial cryptic peptide (mitocryptide) NADH dehydrogenase subunit 4 (MCT-ND4, a mitochondrial-derived formyl peptide; Fig. 2c) and the hexapeptide WKYMVM (Fig. 2d). Despite the fact that the highest concentrations of FPR 2 agonists did not induce the highest degree of amplification of the ZQ16 response, no inhibitory effect on the ZQ16 response was obtained with increasing concentrations of either of the FPR2 agonists tested (Fig. 2b-d). As such, F2 $\mathrm{Pal}_{10}$ was used for further and more detailed characterization of the increased GPR84-mediated ROS response in FPR2-desensitized neutrophils.

The response induced by the ZQ16 analog Cpd51 [23] was also significantly amplified in $\mathrm{F}_{2} \mathrm{Pal}_{10}$-desensitized neutrophils (Fig. 3a), reaching a maximum level already at $\sim 50 \mathrm{~nm} \mathrm{~F} 2 \mathrm{Pal}_{10}$ (Fig. 3b). Furthermore, the magnitude of the ROS production induced by both ZQ16 and Cpd51 in F2Pal ${ }_{10}$-desensitized neutrophils was similar to that induced by $\mathrm{F}_{2} \mathrm{Pal}_{10}$ in naïve neutrophils (Fig. 2a, 3a). However, it should be noted that GPR84 agonists, when compared to $\mathrm{F} 2 \mathrm{Pal}_{10}$, were very 
Fig. 2. Enhanced reactivation induced by ZQ16 in FPR2-desensitized neutrophils. a Naïve neutrophils were first activated with $\mathrm{F}_{2} \mathrm{Pal}_{10}(500 \mathrm{nM}$, solid and dashed lines) or buffer (dotted line), and the release of superoxide anions was measured continuously over time. After $5 \mathrm{~min}$, when the F2Pal ${ }_{10}$ response had returned to basal levels, the neutrophils received a second stimulation with $\mathrm{F}_{2} \mathrm{Pal}_{10}$ (500 nM, dashed lines) or ZQ16 (1 $\mu \mathrm{M}$, solid and dotted lines). One representative experiment out of 5 individual experiments for each agonist combination is shown. b-d Summary of the second response induced by ZQ16 $(1 \mu \mathrm{M})$ from FPR2-desensitized neutrophils pre-activated with different concentrations of $\mathrm{F}_{2} \mathrm{Pal}_{10}$ $(n=5)$ (b), MCT-ND4 $(n=5)$ (c), or WKYMVM $(n=5)(\mathbf{d})$. The second peak superoxide response was determined, and bar graphs show the percentage (mean + SEM) of the naïve ZQ16 response (neutrophils that received buffer as the first stimulation) denoted as a response of $100 \%$ and indicated by the dotted line. Statistically significant differences in $\mathbf{b}-\mathbf{d}$ were assessed using a repeated measures one-way ANOVA followed by Dunnett's multiple comparison test to the naïve ZQ16 response. FPR, formyl peptide receptor; MCT-ND4, mitochondrial cryptic peptide (mitocryptide) NADH dehydrogenase subunit 4.

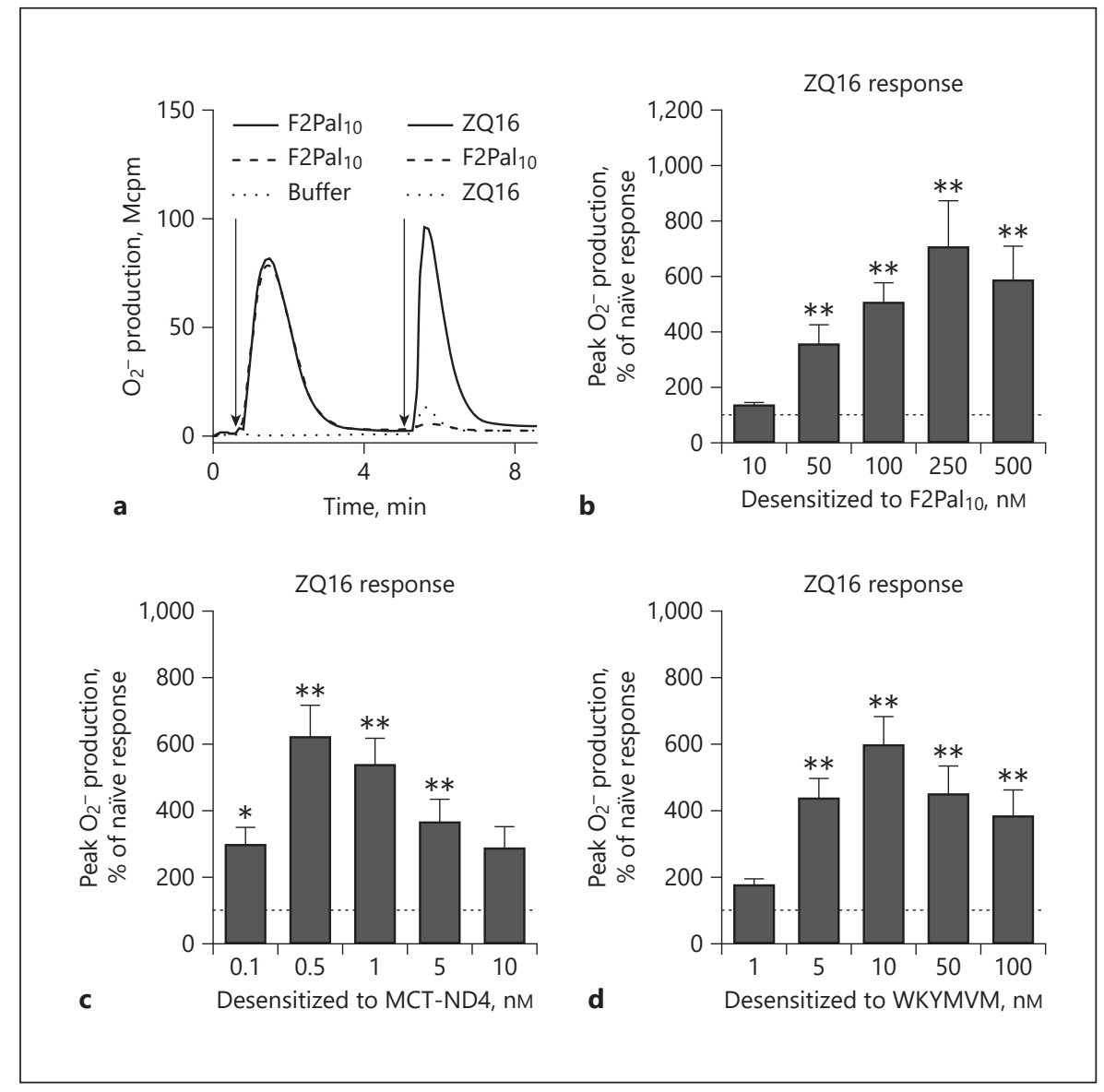

poor ROS inducers in naïve cells (Fig. 1d). In addition, a GPR84 agonist dose-dependent ROS production was observed in neutrophils desensitized with a fixed concentration of $\mathrm{F} 2 \mathrm{Pal}_{10}$. These data revealed that Cpd51 was 1,000 times more potent than ZQ16 in triggering the ROS release from FPR2-desensitized neutrophils $\left(\mathrm{EC}_{50}\right.$ value for Cpd51 was $\sim 0.2 \mathrm{nM}$ [Fig. $3 \mathrm{c}$ ] and $\mathrm{EC}_{50}$ value for ZQ16 $\sim 200 \mathrm{nM}$ [Fig. 3d]). In addition, these data also clearly demonstrate that FPR2-generated signals convert GPR84 agonists from poor to potent ROSactivating agonists.

ROS production induced by FPR2 and GPR84 agonists was further examined in two different experimental setups, in which (i) the 2 agonists were added simultaneously and (ii) the FPR2 agonist was diluted 100× ("washed out") prior GPR84 agonist stimulation of the FPR2-desensitized neutrophils. In the first experimental setup (simultaneous stimulation), relatively low concentrations of F2Pal ${ }_{10}$ and Cpd51 were chosen in order to generate a comparable and detectable response from each individual agonist alone. Using these concentrations and stimu- lating neutrophils with the two agonists simultaneously resulted in a response that was higher in magnitude than each agonist added alone. This increased response induced by simultaneous addition of the two agonists was thus comparable to the sum of the response induced by each individual agonist alone (Fig. 3e). In the second experimental setup, we "washed out" $\mathrm{F} 2 \mathrm{Pal}_{10}$ (by a $100 \times$ dilution after FPR2 desensitization) just prior reactivation by Cpd51. This dilution of $\mathrm{F} 2 \mathrm{Pal}_{10}$ resulted in a decreased Cpd51-induced ROS production by FPR2-desensitized neutrophils (Fig. 3f) to a level similar to the Cpd51-induced response produced by naïve neutrophils (Fig. 3e). Taken together, these data show that the presence of FPR2 agonist is required during the cross-talk-induced reactivation.

\section{GPR84 Triggers a Unidirectional Reactivation of Desensitized FPR2}

To characterize the precise receptor involvement of the amplified GPR84 response in FPR2-desensitized neutrophils, we determined the effects of antagonists specific 


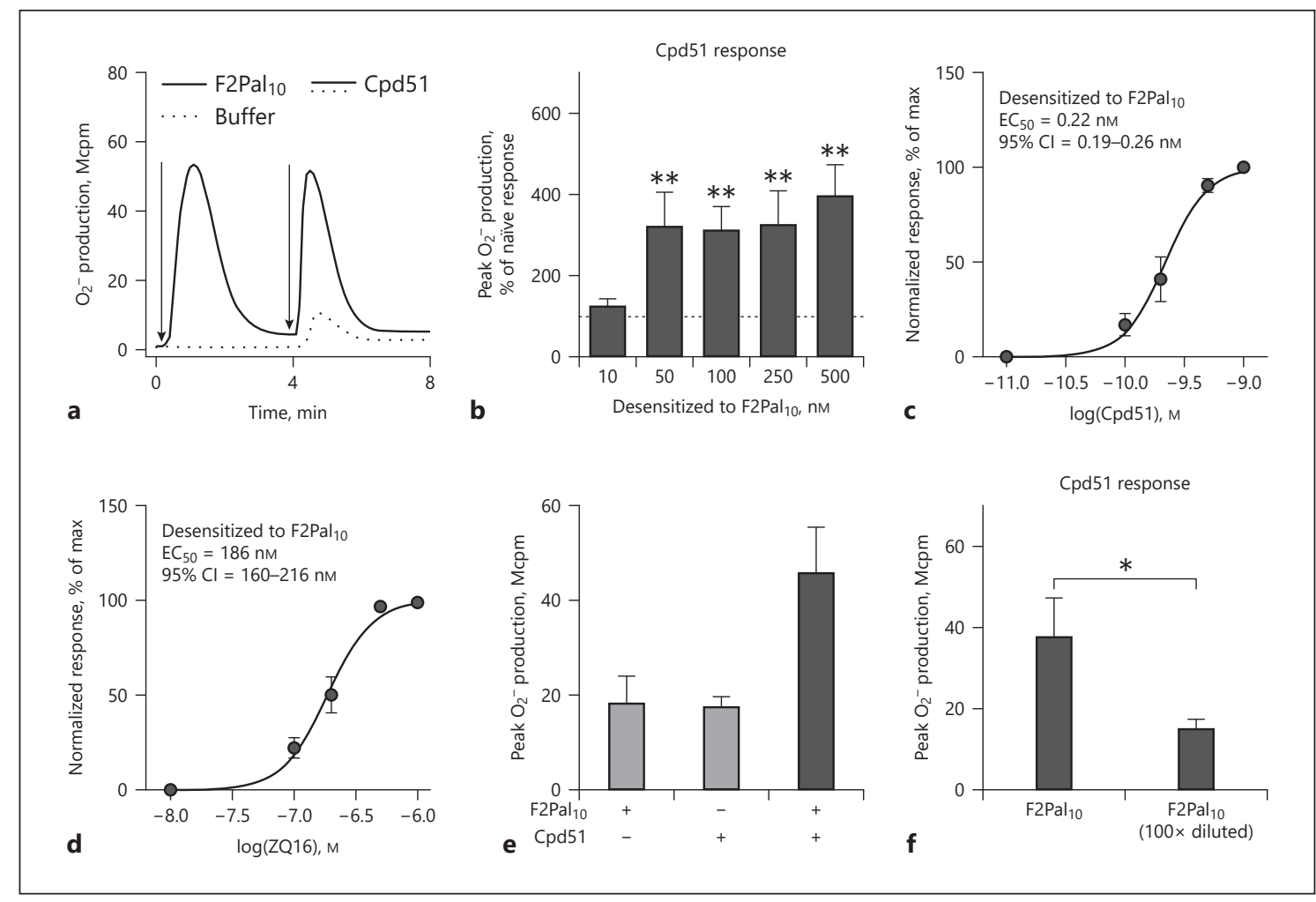

Fig. 3. $\mathrm{F}_{2} \mathrm{Pal}_{10}$ transfers GPR84 agonists into potent NADPH oxidase activators. a Naïve neutrophils were first activated with $\mathrm{F}_{2} \mathrm{Pal}_{10}$ (500 nM, solid line) or buffer (dotted line), and the release of superoxide anions was measured continuously over time. When the $\mathrm{F}_{2} \mathrm{Pal}_{10}$ response had returned to basal levels, the neutrophils received a second stimulation with Cpd51 ( $1 \mathrm{nM}$, solid and dotted lines). One representative experiment out of 4 individual experiments for each agonist combination is shown. $\mathbf{b}$ Summary of the second GPR84-agonist-induced response from neutrophils preactivated with different concentrations $\mathrm{F}_{2} \mathrm{Pal}_{10}$ (mean $+\mathrm{SEM}, n=$ 4). Statistically significant differences from the naïve Cpd51 response were assessed using a one-way ANOVA followed by Dunnett's multiple comparison test to the naïve Cpd51 response (denoted as a response of $100 \%$ and indicated by the dotted line). c, d Dose-response curves of the second response induced by Cpd51 (c) or ZQ16 (d) from FPR2-desensitized cells pre-activated with a fixed concentration of $\mathrm{F}_{2} \mathrm{Pal}_{10}(500 \mathrm{nM})$. Data were normal-

for FPR2 and GPR84, respectively. The receptor selectivity of the two antagonists PBP10 (selective for FPR2; [32]) and GLPG1205 (selective for GPR84; [33]) was confirmed using $\mathrm{F}_{2} \mathrm{Pal}_{10}$ and $\mathrm{Cpd} 51$ as neutrophil-activating agonists. As expected, the FPR2 antagonist inhibited the response induced by $\mathrm{F}_{2} \mathrm{Pal}_{10}$ (Fig. 4a) and was without effect on the response induced by Cpd51 (Fig. 4b), whereas the GPR84 antagonist inhibited the Cpd51 response (Fig. $4 \mathrm{~b}$ ) and was without effect on the $\mathrm{F} 2 \mathrm{Pal}_{10}$-induced response (Fig. 4a). Interestingly, the response induced by ized to the maximal response induced by the respective agonists. The $\mathrm{EC}_{50}$ values and $95 \% \mathrm{CI}$ were calculated based on the peak ROS production (mean + SEM, $n=3$ independent experiments). e Neutrophils were stimulated either alone or simultaneously with F2 $\mathrm{Pal}_{10}(50 \mathrm{nM})$ and Cpd51 (1 nM), and data show the peak response of superoxide production (mean + SEM, $n=6$ ). $\mathbf{f}$ Neutrophils $(10 \mu \mathrm{L})$ desensitized with $\mathrm{F}_{2} \mathrm{Pal}_{10}(500 \mathrm{nM})$ were transferred to a pre-warmed CL reaction mixture $(890 \mu \mathrm{L})$ containing either the same concentration of $\mathrm{F}_{2} \mathrm{Pal}_{10}(500 \mathrm{nM})$ or KRG to obtain a $100 \times$ diluted F2Pal 10 , followed by stimulation with Cpd51 (1 nM). Data are presented as the peak response of superoxide production (mean + SEM, $n=5)$ and statistical analysis was performed by a paired Student's $t$ test. FPR, formyl peptide receptor; ROS, reactive oxygen species; NADPH, nicotine adenine dinucleotide phosphate; CI, confidence interval; CL, chemiluminescence; KRG, KrebsRinger phosphate buffer.

the GPR84 agonist ZQ16 in FPR2-desensitized neutrophils was significantly inhibited by PBP10; the FPR2 antagonist was added at a time point when the $\mathrm{F}_{2} \mathrm{Pal}_{10}$-induced response had been terminated (Fig. 4c, d). The degree of inhibition by PBP10 was comparable to that induced by the GPR84 antagonist GLPG1205, and the inhibited response reached similar levels to those induced by ZQ16 in naïve neutrophils (Fig. 4d). Very similar inhibitory patterns were observed with the two antagonists when ZQ16 was replaced by the other GPR84 agonist 


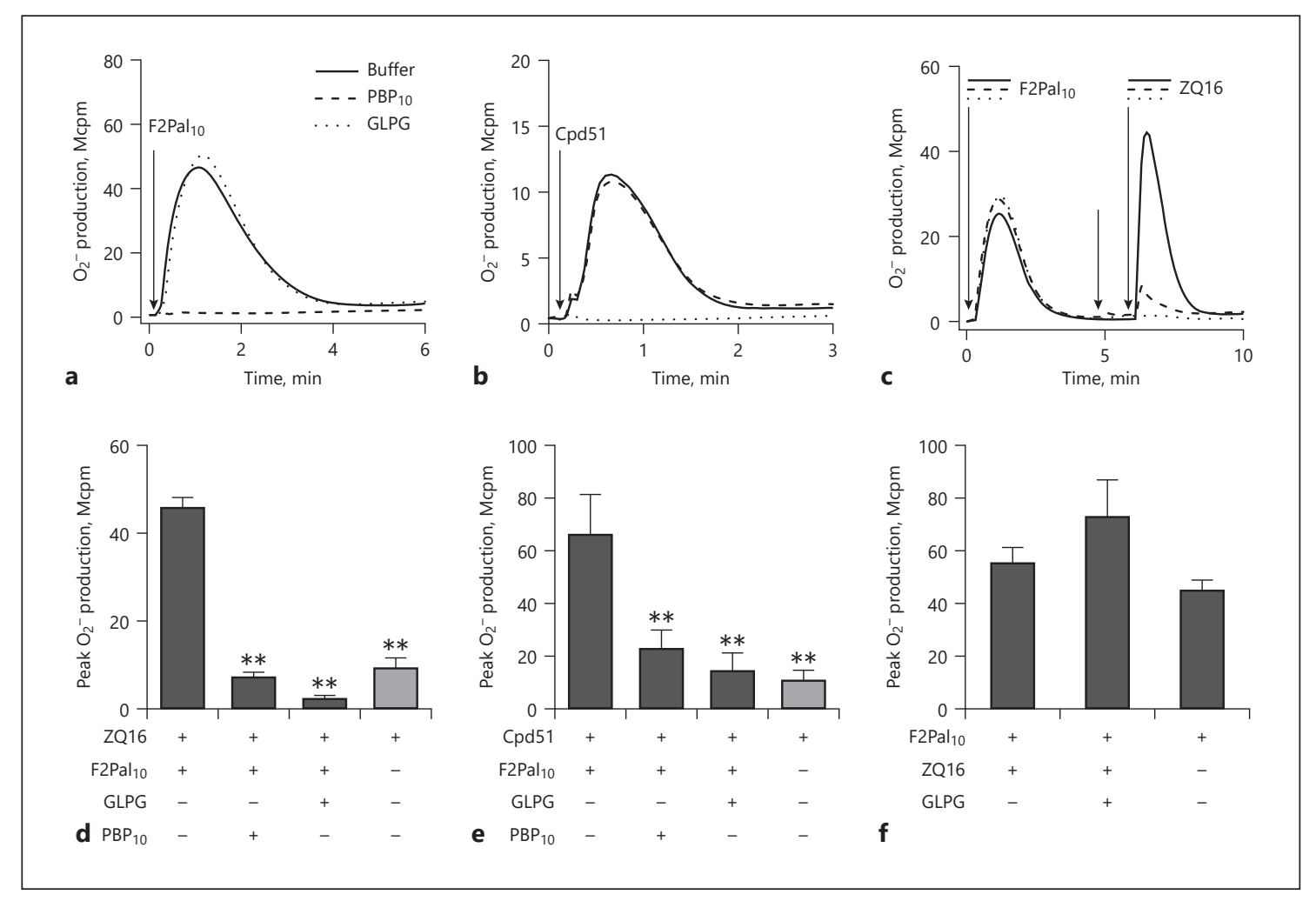

Fig. 4. GPR84 agonists trigger a unidirectional reactivation of F2Pal ${ }_{10}$-desensitized neutrophils. a, b Naïve neutrophils were activated by F2Pal $10(500 \mathrm{nM})(\mathbf{a})$ or Cpd51 (10 nM) (b) in the absence (solid line) or presence (dashed line) of the FPR2-specific inhibitor PBP10 $(1 \mu \mathrm{M})$ or the GPR84-specific antagonist GLPG1205 $(1 \mu \mathrm{M}$, dotted line), and the release of superoxide anions was measured continuously over time. One representative experiment out of 3 individual experiments for each agonist/antagonist combination is shown. c Naïve neutrophils were first activated with F2Pal ${ }_{10}(500$ $\mathrm{nM}$, first arrow). When the response had declined, cells received a second treatment with the FPR2-specific inhibitor PBP10 $(1 \mu \mathrm{M}$, dashed line), the GPR84 inhibitor GLPG1205 (1 $\mu \mathrm{M}$, dotted line), or buffer (solid line) for $1 \mathrm{~min}$ (time of addition is indicated by second arrow), followed by a second stimulation with ZQ16 ( $1 \mu \mathrm{M}$, time of addition is indicated by the third arrow). One representative experiment out of 3 individual experiments for each agonist/antagonist combination is shown. d, e Summary of the inhibitory effects by receptor-specific antagonists on the second response induced by ZQ16 (1 $\mu \mathrm{M})(\mathbf{d})$ and Cpd51 (100 nM) (e) from F2Pal ${ }_{10}$-desensitized

Cpd51 (Fig. 4e). These data thus suggest that GPR84 can cross-talk with FPR2 and the GPR84-mediated ROS production in FPR2-desensitized neutrophils involves a reactivation of desensitized FPR2. In addition, the GPR84 antagonist was without effect when the order of the activating agonists was reversed. That is, the $\mathrm{F} 2 \mathrm{Pal}_{10}$ response in GPR84-desensitized neutrophils was not affected by the GPR84 antagonist (Fig. 4f). This strongly implies that neutrophils $(n=3-5)$. The naïve ZQ16 or Cpd51 response from neutrophils stimulated in the absence of $\mathrm{F}_{2} \mathrm{Pal}_{10}$ and inhibitors is included for comparison (light grey bars). Data are expressed as peak superoxide production (mean + SEM), and statistically significant differences were assessed using a repeated measures oneway ANOVA followed by Dunnett's multiple comparison test to the GPR84-agonist-induced response in $\mathrm{F}_{2} \mathrm{Pal}_{10}$-desensitized cells in the absence of inhibitors. $\mathbf{f}$ Reversed order of receptor agonist addition, that is, naive neutrophils were first activated with buffer or the GPR84 agonist ZQ16 (1 $\mu \mathrm{M})$. Once the ZQ16 response had declined to base level, the cells received a second stimulation with the FPR2 agonist F2Pal 10 (500 nM). The GPR84 antagonist GLPG1205 (1 $\mu \mathrm{M})$ was added 1 min before the second $\mathrm{F} 2 \mathrm{Pal}_{10}$ stimulation. The bar graph shows the peak of the second $\mathrm{F} 2 \mathrm{Pal}_{10}$-induced superoxide response (mean + SEM, $n=3$ ). Statistically significant differences were assessed using a repeated measures one-way ANOVA followed by Dunnett's multiple comparison test to the $\mathrm{F} 2 \mathrm{Pal}_{10}$-induced response in ZQ16-desensitized cells in the absence of GLPG1205. FPR, formyl peptide receptor.

the receptor cross-talk is unidirectional, that is, GPR84 transduces signals, leading to FPR2 reactivation but not vice versa.

\section{The FPR2 Reactivation Signals Are Sensitive to} Calyculin A and Bypass $\beta$-Arrestin Recruitment

Recent research show that the signals generated by agonist occupied GPCRs differ depending on the ago- 


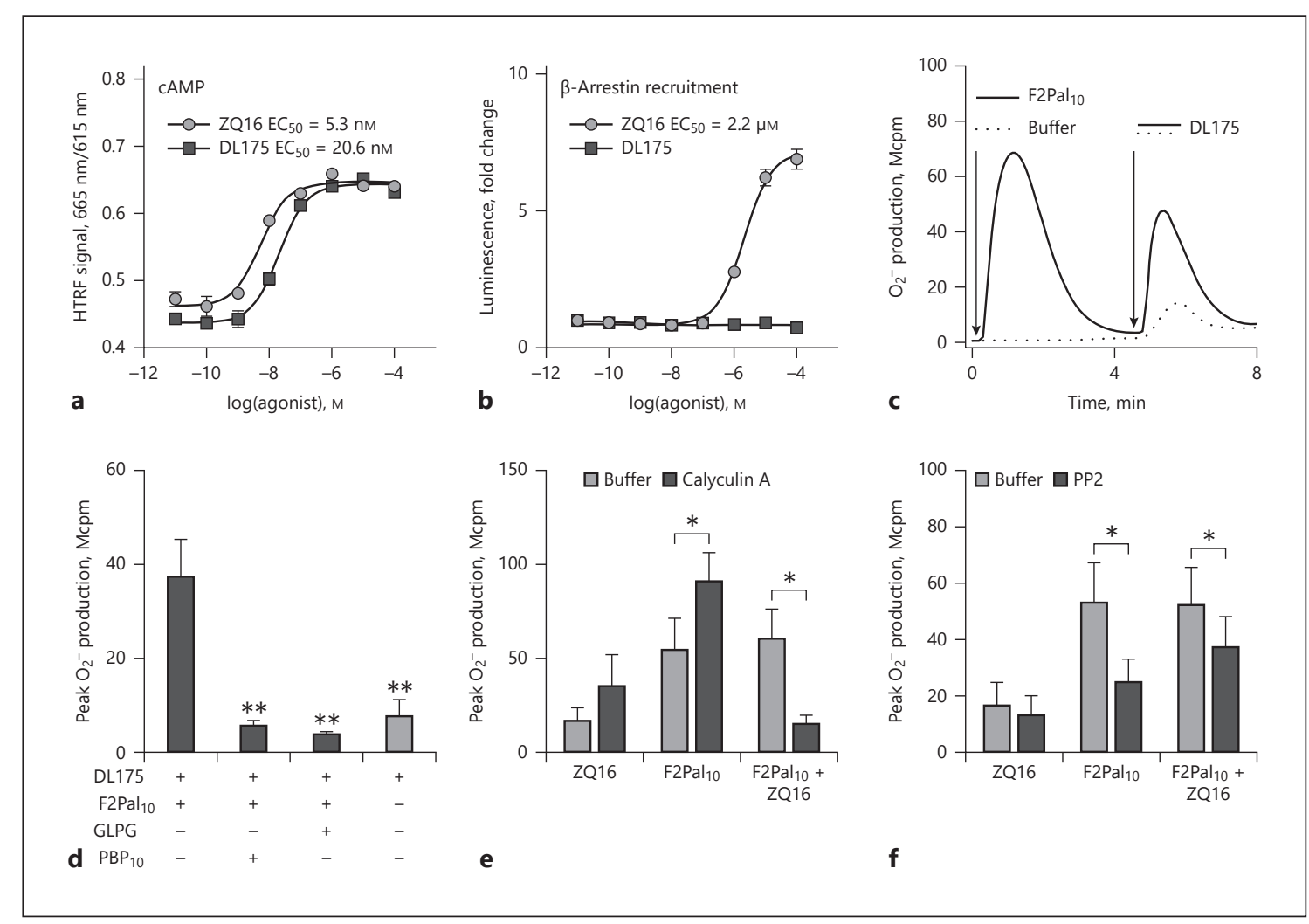

Fig. 5. FPR2 reactivation through GPR84 occurs independent of GPR84-induced $\beta$-arrestin recruitment and involves calyculin Asensitive phosphatases. a, b GPR84-overexpressing HEK293 cells were activated with different concentrations of ZQ16 or DL175. Dose-response curves of agonist-induced cAMP (a) or recruitment of $\beta$-arrestin (b) were measured. The $\mathrm{EC}_{50}$ values were calculated (mean + SEM, $n=3$ independent experiments). c Neutrophils were first activated with $\mathrm{F} 2 \mathrm{Pal}_{10}(500 \mathrm{nM}$, solid line) or buffer (dotted line), and the release of superoxide anions was measured continuously over time. After $5 \mathrm{~min}$, when the $\mathrm{F}_{2} \mathrm{Pal}_{10}$ response had returned to basal levels, the neutrophils received a second stimulation with DL175 (5 $\mu \mathrm{M})$. One representative experiment out of 4 individual experiments is shown. $\mathbf{d}$ The bar graph shows summary of the second peak DL175-induced superoxide response from $\mathrm{F} 2 \mathrm{Pal}_{10}$-desensitized neutrophils treated for $1 \mathrm{~min}$ with or without GLPG1205 $(1 \mu \mathrm{M})$ or PBP10 $(1 \mu \mathrm{M})$ prior DL175 stimulation (mean + SEM, $n=4)$. The naïve DL175 response from neutrophils stimulated in the absence of $\mathrm{F} 2 \mathrm{Pal}_{10}$ and inhibitors is in-

nist that initiates signaling, of which some, in addition to activating the heterotrimeric $\mathrm{G}$ protein, may also recruit $\beta$-arrestin to initiate noncanonical signaling [34]. The FPR2 agonist F2Pal 10 activates a Gai-containing G-proteins but lacks the ability to recruit $\beta$-arrestin, and the signals downstream the activated receptor are thus biased $[17,35,36]$. The data obtained using F2Pal ${ }_{10}$ as an FPR2-desensitizing agent clearly show that $\beta$-arrestin recruitment downstream FPR2 is not a fea- cluded for comparison (light grey bar). Statistically significant differences were assessed using a repeated measures one-way ANOVA followed by Dunnett's multiple comparison test to the DL175 response in $\mathrm{F}_{2} \mathrm{Pal}_{10}$-desensitized cells in the absence of inhibitors. Neutrophils preincubated with buffer (light grey bars). Calyculin A (60 nM, 10 min, dark grey bars) (e) and PP2 (500 nM, 10 min, dark grey bars) (f) were activated with F2Pal ${ }_{10}(500 \mathrm{nM})$ or buffer (naïve cells) before triggered by ZQ16 $(1 \mu \mathrm{M})$ or F2Pal $10(500 \mathrm{nM})$. The bar graphs (mean + SEM, $n=4$ ) show the peak superoxide release induced by $\mathrm{F} 2 \mathrm{Pal}_{10}$ and $\mathrm{ZQ} 16$ in naïve neutrophils as well as by ZQ16 in $\mathrm{F} 2 \mathrm{Pal}_{10}$-desensitized neutrophils, pretreated in the absence (light grey bars) and presence of calyculin A or PP2 (dark grey bars). The effects of pharmacological inhibitors in comparison to buffer-treated cells for each agonist combination (buffer/ $\mathrm{ZQ16}$, buffer/F2Pal 10 , and $\left.\mathrm{F} 2 \mathrm{Pal}_{10} / \mathrm{ZQ} 16\right)$ were analyzed by a paired Student's $t$ test. FPR, formyl peptide receptor; cAMP, cyclic adenosine monophosphate.

ture that is required for the amplification of the GPR84 response.

To investigate the importance of $\beta$-arrestin recruitment for the ability of GPR84-mediated receptor crosstalk with desensitized FPR2s, we determined the crosstalk activation induced by DL175, a compound recognized by GPR 84 and recently demonstrated to lack the ability to recruit $\beta$-arrestin [24]. We could confirm the described GPR84 signaling property of DL175, as dem- 
onstrated by a strong signaling bias toward the G-protein-cAMP pathway (signaling achieved without any $\beta$-arrestin recruitment) also with high concentrations $(100 \mu \mathrm{M})$ of DL175 (Fig. 5a, b). The signaling pattern of DL175 was opposite to the signaling characteristics of ZQ16, which triggers GPR84 downstream activation of the Gai signaling pathway as well as recruitment of $\beta$-arrestin with $\mathrm{EC}_{50}$ values of $\sim 5 \mathrm{nM}$ and $\sim 2 \mu \mathrm{M}$, respectively (Fig. 5a, b). Despite the signaling bias of DL175 away from $\beta$-arrestin recruitment, the DL175-induced ROS response was robustly amplified in FPR2-desensitized neutrophils (Fig. 5c). Further, also this DL175 response was inhibited not only by the GPR 84 antagonist but also by the FPR2 antagonist PBP10, and the level of response reached in the presence of PBP10 was comparable to that induced by DL175 in naive neutrophils (Fig. 5d). Thus, the data obtained with DL175 show that although this GPR84 agonist is unable to recruit $\beta$-arrestin downstream of GPR84, the signals generated reactivate desensitized FPR2. Together with the fact that F2Pal ${ }_{10}$ also lacks ability to recruit $\beta$-arrestin, we conclude that $\beta$-arrestin does not play a role in the receptor cross-talkinduced FPR2-reactivation process.

To gain further insights into the intracellular signals involved in the receptor cross-talk transduced by GPR84 and leading to reactivation of the desensitized FPR2, the effects of two pharmacological inhibitors that potently inhibit PP2A/PP1 phosphatases (calyculin A) and Src kinases (PP2), respectively, were determined. F2Pal ${ }_{10}$-desensitized neutrophils were treated with specific pharmacological inhibitors, followed by FPR2 reactivation with the GPR84 agonist ZQ16. The presence of calyculin A significantly reduced the cross-talk-induced ROS production (Fig. 5e). Of note, this was not only due to an inhibition on the naïve GPR84 or FPR2 response, as the effect of calyculin A, if any, on the ZQ16- and F2Pal ${ }_{10^{-}}$ induced ROS production in naïve non-desensitized neutrophils was increased rather than reduced (Fig. 5e). The Src kinase inhibitor PP2 reduced the naïve $\mathrm{F} 2 \mathrm{Pal}_{10}$ response as well as the receptor cross-talk-induced ROS production (Fig. 5f). Taken together, these data show that, at the signaling level, $\beta$-arrestin is not involved in the GPR84-mediated FPR2 reactivation, a process that engages calyculin A-sensitive phosphatases.

ROS Production Induced by GPR84 Agonists in FPR1Desensitized Neutrophils

Previous studies of FPR signaling (summarized in some recent reviews $[3,37]$ ) have shown that the two neutrophil FPRs (FPR1 and FPR2) regulate the activity of the neutrophil NADPH oxidase in almost identical manners [38]. In accordance with this, desensitized FPR1 and FPR2 both are reactivated by signals generated by the agonist-occupied PAFR (shown for FPR1 in Fig. 6a) and the primed PAF response is inhibited not only by a PAFR antagonist but also by an FPR-specific antagonist [39]. Thus, a process of receptor cross-talk-induced receptor reactivation is disclosed for both FPR1 and FPR2 [3]. The basic characteristics of this process are shared by the GPR84 agonist-triggered activation of FPR2-desensitized neutrophils (Fig. 2, 4). Based on these facts, we assumed that also the desensitized FPR1 should be reactivated by agonist-occupied GPR84 and that the receptor cross-talk should result in an amplification of the neutrophil response as a result of FPR1 reactivation. Using the FPR2 desensitization and GPR84 agonist-induced reactivation protocol but with the FPR2 agonist replaced by the potent FPR1-specific agonist AMIFL, we found, however, that the response by GPR84 agonists induced in FPR1-desensitized neutrophils was unaffected or even reduced (Fig. 6b, c). We intentionally used low nanomolar range concentrations $(0.1-10 \mathrm{nM})$ of fMIFL, as this peptide is a full agonist with an $\mathrm{EC}_{50}$ of $\sim 0.1 \mathrm{nM}$ [40]. Similar heterologous receptor cross-talk activation profile obtained with FPR1-desensitized neutrophils and ZQ16 was obtained when this GPR84 agonist was replaced with the other GPR84 agonist Cpd51 (Fig. 6d) and when the FPR1 agonist fMIFL was replaced with the most commonly used FPR1 agonist fMLF as desensitizing agent (Fig. 6e).

The responses induced by GPR84 agonists in FPR-desensitized neutrophils highlight a fundamental difference between the two FPRs in relation to GPR84, a difference that is clearly seen when the concentrations of the FPR agonists used generate a full or near full neutrophil response. As shown in Figure 2, the GPR84-triggered response in FPR2-desensitized neutrophils was as pronounced or even higher (for ZQ16) than that induced by $\mathrm{F} 2 \mathrm{Pal}_{10}$ in naïve neutrophils. In contrast, the GPR84-triggered response in neutrophils desensitized with corresponding high concentrations of an FPR1 agonist was not increased but rather suppressed (Fig. 6b-e). It should be noted, however, that when the desensitizing FPR1 agonist concentration was reduced, the GPR84-induced response was somewhat potentiated (Fig. 6c-e). The modest potentiation of the ZQ16 response in PMIFL (10 pM) desensitized cells was sensitive to the FPR1 antagonist cyclosporine $\mathrm{H}$ (Fig. 6f), suggesting that a reactivation of the desensitized FPR1 is achieved when the desensitizing agonist fMIFL concentration is too low to heterologously desensitize GPR84. 


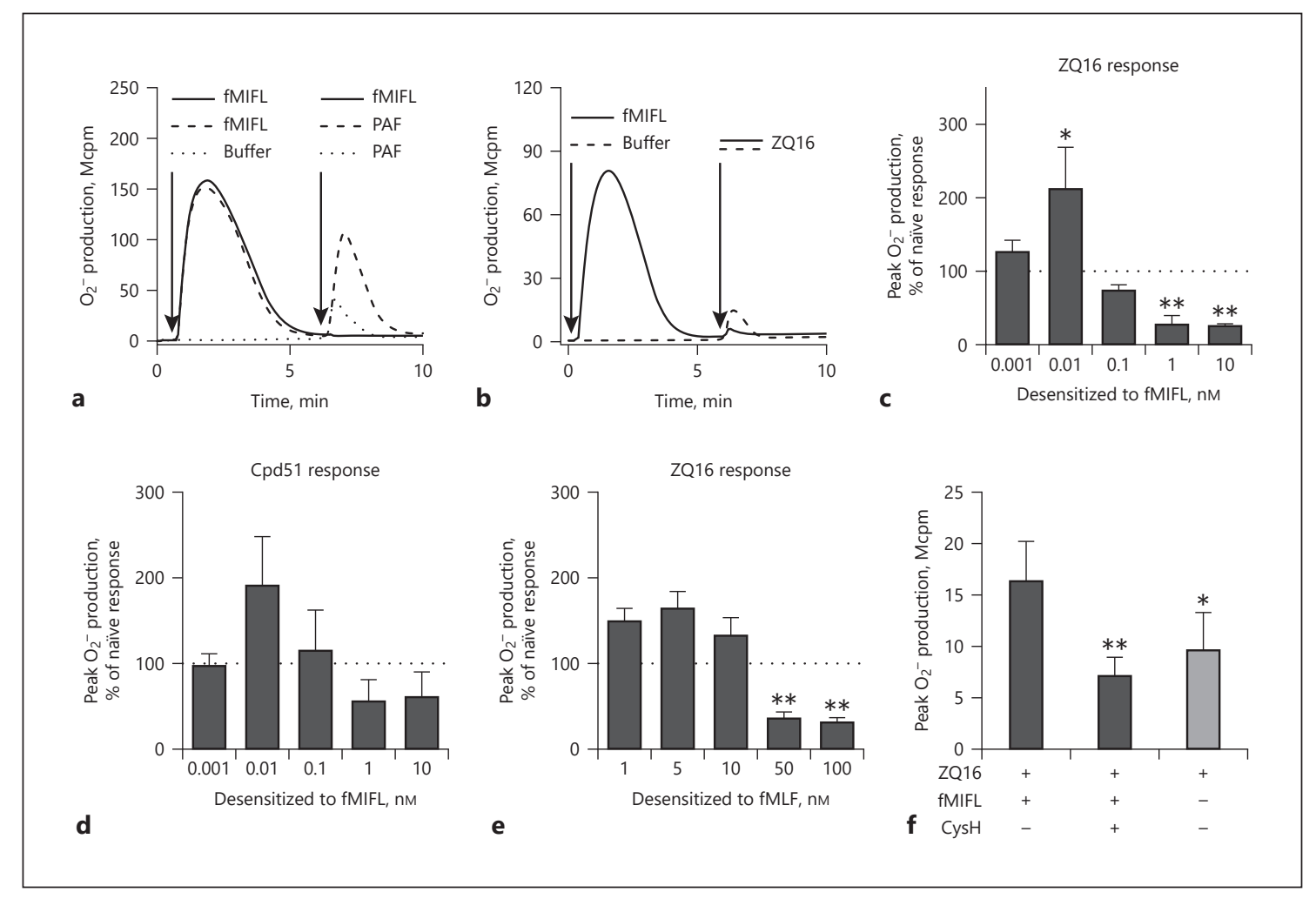

Fig. 6. Cross-talk between FPR1 and GPR84. a Neutrophils were first stimulated with fMIFL (10 nM, solid and dashed lines, time of addition indicated by the first arrow) or buffer (dotted line). When the responses had returned to basal levels, the cells received a second stimulation (time of addition indicated by the second arrow) with fMIFL (10 nM, solid line) or PAF (100 nM, dashed and dotted lines). One representative experiment is shown. b Neutrophils were activated with fMIFL ( $10 \mathrm{nM}$, solid line, time of addition indicated by the first arrow) or buffer (dashed line). Once the fMIFL response had returned to base level, the cells received a second stimulation with ZQ16 $(1 \mu \mathrm{M}$, time of addition indicated with the second arrow). One representative experiment out of 4 individual experiments for each agonist combination is shown. c-e The bar graphs (mean + SEM, $n=5-9)$ show a summary of the second ROS response induced by ZQ16 (1 $\mu \mathrm{M})(\mathbf{c})$ or Cpd51 (1 nM) (d) in neutrophils pre-activated/desensitized with different concentrations of fMIFL and induced by ZQ16 $(1 \mu \mathrm{M})$ in neutrophils desensitized with different concentrations of $\mathrm{fMLF}(\mathbf{e})$. The data are expressed as \% of the naïve GPR 84 agonist response (the dotted lines indicate the $100 \%$ of naïve response, peak superoxide production induced

We and others have earlier shown that inflammatory mediators including the FPR agonists FMLF and WKYMVM are redox sensitive and that their biological activity can be inactivated by neutrophil ROS through peptide oxidation [41-43]. To examine whether the different levels of ROS produced through cross-talk between the two FPRs and GPR84 have a direct relevance in causing inac- by GPR84 agonists in the absence of FPR1 agonists). To adjust for the increased background levels after FPR1 stimulation, the baseline activity just before the second stimulation was subtracted from the second GPR84 agonist-induced peak superoxide responses. Statistically significant differences were assessed using a repeated measures one-way ANOVA followed by Dunnett's multiple comparison to the naïv GPR84 response. f Neutrophils were stimulated with buffer (naïve neutrophils) or pre-activated/desensitized with fMIFL ( $0.01 \mathrm{nM})$. Once the fMIFL-induced superoxide release had declined, the cells received a second treatment with buffer or the FPR1 antagonist CysH $(1 \mu \mathrm{M})$ for $1 \mathrm{~min}$ followed by a second stimulation with ZQ16 $(1 \mu \mathrm{M})$. The bar graph shows the second peak superoxide response (mean $+\mathrm{SEM}, n=3$ ) with the naïve ZQ16 response (light grey bar) included for comparison. Statistically significant differences were assessed using a repeated measures one-way ANOVA followed by Dunnett's multiple comparison to the ZQ16-induced response in fMIFL-desensitized cells in the absence of $\mathrm{CysH}$. FPR, formyl peptide receptor; formylated tetrapeptide $\mathrm{N}$-formyl-Met-Ile-Phe-Leu; ROS, reactive oxygen species; CysH, cyclosporine $\mathrm{H}$.

tivation of the FPR agonists, we performed ROS inactivation experiments as described earlier [43]. FPRs desensitized with AMLF or WKYMVM were reactivated with Cpd51, and the remaining activity of fMLF or WKYMVM after oxidation was determined by their potential to activate ROS release from a new batch of naïve neutrophils. We found that supernatant from cells desensitized 
with WKYMVM followed by GPR84 agonist-induced reactivation contained less active peptide agonist than that from cells exposed to fMLF and Cpd51 (see online suppl. Fig. 1a, b; see www.karger.com/doi/10.1159/000514887 for all online suppl. material). This is in line with the described role of ROS in peptide inactivation, that is, a more pronounced inactivation of WKYMVM is induced by the higher level of ROS generated through GPR84-induced FPR2 reactivation. Our earlier published data have demonstrated that in naïve cells, fMLF and WKYMVM trigger very similar levels of ROS release with a ratio close to 1 ([38], online suppl. Fig. 1c, d). These data thus further support the biological role of ROS in mediating inactivation of peptide agonists.

Taken together, our data clearly show that both FPR2 and FPR1 can communicate with GPR84 to regulate ROS production in human neutrophils. In addition, it is obvious that whereas the GPR84-triggered ROS production is amplified in FPR2-desensitized neutrophils, FPR1 agonists primarily desensitize GPR84.

\section{Discussion}

Agonists recognized by medium-chain fatty acid receptor GPR84 are fairly poor activators of the ROS-generating NADPH oxidase in naïve neutrophils, but the agonists are transferred to potent activators of the oxidase in FPR2-desensitized neutrophils. The augmentation of the GPR84-triggered response is achieved through an earlier described receptor cross-talk mechanism in neutrophils $[3,16]$, initiated by receptor downstream signals generated by GPR84 that reactivate the desensitized FPR2. Neutrophils express, in addition to FPR2, the closely related FPR1, and although both receptors recognize $N$-formylated peptides, their respective orthosteric agonist binding pockets differ and by that they have different agonist recognition profiles [30]. In accordance with the large similarities between these receptors in their cytoplasmic domains [37], signaling by the two receptors, in particular regarding neutrophil ROS production, has been shown to be very similar or even qualitatively identical in our earlier studies [38]. This study reveals, however, a fundamental difference between FPR1 and FPR2 in their respective communication with GPR84. An indepth characterization of the receptor cross-talk patterns shows that GPR84 utilizes signaling through a pathway that triggers a reactivation of desensitized FPR2 and by that GPR84 agonists independent of their ability to recruit $\beta$-arrestin are transferred to potent inducers of ROS production. Despite the fact that the signals generated by GPR84 can also reactivate FPR1-desensitized neutrophils, this receptor primarily suppress ROS production induced by GPR84 agonists. As the FPRs and GPR84 are emerging as promising targets for treating inflammationassociated diseases $[22,44]$, the novel receptor cross-talk between the two FPRs and GPR84 described will increase the understanding of the complex signaling network that regulates GPCR-mediated neutrophil activation and the inflammatory response.

The neutrophil production/release of ROS induced by FPR agonists follows a typical GPCR-mediated response pattern in neutrophils, that is, the time for an active ROS production/release is rather short and the response is after a period of minutes fairly rapidly terminated through homologous receptor desensitization [45]. Accordingly, the homologous FPR-desensitized neutrophils are no longer responsive to an activation by the same agonist or to another agonist that binds to the same receptor. In this study, we investigated the regulatory mechanisms of FPRs cross-talk with GPR84 in regulating the ROS-generating enzyme system in human neutrophils, a system that has many biological implications. ROS has a broad clinical relevance in several different medical conditions, such as cancer, inflammatory diseases, and autoimmune diseases. For example, it has been shown that patients with chronic granulomatous disease with diminished/ abolished ROS production suffer from hyperinflammatory conditions and that individuals carrying $\mathrm{p} 47^{\text {phox }}$ gene polymorphism are prone to develop autoimmune disease $[7,9,46,47]$. In addition, ROS can directly affect tumor-killing activity of lymphocytes in cancer, and depending on the level of ROS produced, metastasis and cancer growth are either increased or constrained [48, 49]. FPR-desensitized neutrophils produce/release, however, ROS when activated by an agonist that is recognized by the PAFR. In fact, PAF is a poor activator of naïve neutrophils, but this agonist is turned into a potent activator of the ROS-producing system in FPR1- as well as FPR2desensitized neutrophils $[16,39]$. It is clear that the level of ROS produced by naïve neutrophils when activated by specific GPR84 agonists (both ZQ16 and the structurally related analog Cpd51) is fairly low and almost negligible as compared to the ROS release following neutrophil activation with agonists specifically recognized by FPR 1 or FPR2. Interestingly, we show that the response induced by GPR84 agonists shares the same activation profile as PAF in relation to FPR2-desensitized neutrophils, characterized by an amplification of the response that reaches levels comparable to that induced by FPR agonists in na- 
ive neutrophils. The fact that this amplification applied to several different FPR2- as well as GPR84-specific agonists suggests that the effect lies at the receptor level and is independent of the particular agonist pair used to desensitize FPR2 and activate GPR84, respectively. Although it is known that FPR2 has the capacity to regulate the functions of many other GPCRs in human neutrophils [3], the interplay between FPR2 and GPR84 has previously not been studied. Thus, this study does not only put GPR84 on the list of GPCRs that can cross-talk with FPRs but also further support the emerging notion that GPCR activity is regulated at multiples levels through complex mechanisms.

We have earlier described the regulatory role of FPRs and the position they have in the receptor hierarchy to the other neutrophil receptors such as PAFR and ATP receptor $\mathrm{P}_{2} \mathrm{Y}_{2} \mathrm{R}[3,15-17,30,39]$. Based on the results presented in these studies, we have put forward a receptor signaling cross-talk activation model for reactivation of desensitized FPRs; reactivation of FPRs is initiated by agonist binding to the PAFR/P2 $\mathrm{Y}_{2} \mathrm{R}$, and the signals generated downstream of the G-protein activated by these receptors activate the desensitized FPRs from the cytosolic side of the membrane [3]. Even though the precise signals leading to an amplified GPR84 response in FPR2-desensitized neutrophils remain to be elucidated, the results obtained with these two receptors together fit perfectly to our receptor signaling cross-talk activation model for receptor reactivation. Further, it is clear from the data presented that the reactivation signals utilized in the described cross-talk are not the same as those used by FPRs to directly activate the NADPH oxidase. This is illustrated by the fact that calyculin A, a specific phosphatase inhibitor earlier shown to potentiate the response induced in naïve neutrophils, blocks the cross-talk signaling, leading to reactivation of FPR2-desensitized neutrophils not only when PAF is used to activate the neutrophils [16] but also with the reactivation is induced by GPR 84 agonists. To further identify signaling pathways of importance for the GPR84-triggered reactivation of desensitized FPR2, we included a biased GPR84 agonist (DL175) unable to trigger recruitment of $\beta$-arrestin. The data obtained using DL175 showed that the receptor downstream signals generated by GPR84 reactivate FPR2-desensitized neutrophils also with this agonist, which suggests that the reactivating signal(s) is generated independent of $\beta$-arrestin recruitment. The fact that also neutrophils activated/desensitized with FPR2 agonists unable to recruit $\beta$-arrestin (e.g., $\mathrm{F} 2 \mathrm{Pal}_{10}$ and PSM $\alpha 2$ )

Communication between Neutrophil G Protein-Coupled Receptors are reactivated by the receptor cross-talk signals generated by GPR84 (this study) as well as by PAFR and $\mathrm{P}_{2} \mathrm{Y}_{2} \mathrm{R}[15-17,36]$ shows that $\beta$-arrestin is not at all involved in the receptor cross-talk reactivation of FPR2. It would be highly interesting to explore the effect on neutrophil activation of a biased GPR84 agonist that is in favor of $\beta$-arrestin recruitment, but to our knowledge, such a biased agonist has not yet been identified.

Neutrophils express two structurally very similar FPRs (FPR1 and FPR2), and the two receptors also share many similarities regarding the transduced receptor downstream signals as well as the cellular responses [30, 37]. Earlier data obtained in studies designed to determine receptor hierarchies suggest that FPR1 has the same position as FPR2 in the neutrophil GPCR hierarchy. This suggestion is, however, challenged by the results presented in this study. It is clear that FPR1-desensitized neutrophils similar to FPR2-desensitized neutrophils can be reactivated by the receptor cross-talk reactivation signals generated by GPR84, giving rise to an amplified ROS response. However, in contrast to FPR2, this can only be achieved with low concentrations of the FPR1 agonist ( $\sim 0.01$ and $\sim 5 \mathrm{nM}$ for fMIFL and fMLF, respectively), well below the $\mathrm{EC}_{50}$ concentrations for activation with these agonists $(0.1$ and $50 \mathrm{nM}$ for fMIFL and fMLF, respectively [40]). In contrast, the very low response induced by GPR84 agonists in naïve neutrophils is not affected or even reduced when the desensitized state is induced by higher concentrations of the FPR1 agonists. The mechanisms that regulate the functional duality of the FPR1 agonists, having the capacity to reduce the activity induced by GPR 84 agonists on the one hand and on the other hand allow a reactivation of FPR1-desensitized neutrophils, remains to be elucidated. Speculatively, one possibility is that the desensitized states of both FPR1 and FPR2 are transferred to active signaling states, provided that the receptor reactivation signals are generated. As such, no signal would be generated by GPR 84 when high concentrations of the FPR1 agonist have been used to desensitize the receptor. That would mean that the non-responding heterologous desensitized state of GPR84 is generated by high concentrations of FPR1 agonists, whereas FPR2 lacks the ability to desensitize GPR84 irrespectively of concentration. The non-responding heterologous desensitized state of GPR84, induced by higher concentrations of FPR1 agonists, places GPR84 in the same hierarchy category as CXCR1/2 (receptor for IL-8) that has been shown to be regulated in a similar fashion, that is, the so-called endpoint chemoattractants specific for 
FPR1 heterologously desensitize the neutrophil response to agonist recognized by CXCR1/2 [11-14]. The fact that GPR84 generates receptor cross-talk signals that reactivate FPR1 neutrophils desensitized with lower concentrations of FPR1 agonists suggests that no heterologous GPR84 desensitization is induced by such concentrations of the FPR1 agonists, whereas the ability to be reactivated remains. The outcome of the GPR84triggered response in FPR1-desensitized neutrophils would then be dependent on whether the FPR1 agonist concentration used to desensitize FPR1 is also sufficient to desensitize GPR84 or not. The distinct different receptor cross-talk patterns between FPR1 and FPR2 further highlight the emerging novel aspects of the two FPRs in modulating signaling and inflammation in different disease conditions $[3,50,51]$. Mechanistically, the communication between receptors is undoubtedly a highly regulated process that occurs at multiple levels, and no universal mechanism is responsible for the different cross-talk processes. Among many proposed mechanisms and signals involved in receptor cross-talk, receptor cross-phosphorylation by protein kinases such as protein kinase $\mathrm{C}$ or $\mathrm{G}$-protein-coupled receptor kinases that are activated by another receptor upon agonist binding has been suggested to play important roles in heterologous desensitization [52, 53]. Future studies should examine the role of different isoforms of G-protein-coupled receptor kinases in regulating FPR desensitization and reactivation and should also explore whether our findings on neutrophils have also implications in other cellular systems including fibroblast expressing both FPRs and GPR84 [54, 55]. Among the known cross-talk patterns, heterologous desensitization of one receptor upon activation of another receptor is more commonly noticed, compared to receptor reactivation by signals generated downstream another receptor, which is less frequently observed. More mechanistic studies such as network-based global signaling analysis and advanced experimental designs in primary human cells are highly desired.

In summary, our data further support that receptor cross-talk between different GPCRs represents an important mechanism to control neutrophil function. Our results of the receptor cross-talk signaling patterns mediated by GPR84-specific agonists in FPR-desensitized neutrophils reveal a not earlier described signaling difference between FPR1 and the closely related FPR2. Understanding the complex mechanisms underlying receptor communication and intracellular signaling pathways in neutrophils should undoubtedly increase our knowledge of GPCR signaling. In addition, increased knowledge of how such responses are modulated in general would facilitate the development of better GPCR-based functional regulators that can be used to control a wide array of pathologies.

\section{Acknowledgement}

We thank Senior Prof. Claes Dahlgren for his critical discussions and valuable suggestions during preparation of the manuscript.

\section{Statement of Ethics}

This study was conducted using human blood neutrophils from buffy coats obtained from the blood bank at the Sahlgrenska University Hospital, Gothenburg, Sweden. The Swedish legislation section code $4 \S 3$ p SFS 2003:460 (Lag om etikprövning av forskning som avser människor) states that no ethical approval is needed for research on buffy coats, as they were provided anonymously and thereby cannot be linked to a specific donor.

\section{Conflict of Interest Statement}

The authors declare that there is no conflict of interest.

\section{Funding Sources}

This work was supported by the Swedish Research Council, the Swedish government under the ALF agreement, the Elisabeth and Alfred Ahlqvist's foundation - Swedish Pharmacy Society grant, the Rune and Ulla Almlövs Foundation grant, the Magnus Bergvall Foundation grant, the IngaBritt and Arne Lundberg Foundation, and National Science Foundation of China (Grant No. 81970341). A.M. is supported by a scholarship from the Novo Nordisk Foundation.

\section{Author Contributions}

H.F., L.B., M.S., and J.M. designed and oversaw all aspects of the study. J.M., M.S., A.M., L.I., L.Z., and L.B. performed and analyzed the experiments with input from T.U., X.X., and H.F. H.F. wrote the first draft, and all authors revised the manuscript and approved the final version prior submission. 


\section{References}

1 Kolaczkowska E, Kubes P. Neutrophil recruitment and function in health and inflammation. Nat Rev Immunol. 2013;13(3):15975.

2 Mayadas TN, Cullere X, Lowell CA. The multifaceted functions of neutrophils. Annu Rev Pathol. 2014;9:181-218.

3 Dahlgren C, Holdfeldt A, Lind S, Mårtensson J, Gabl M, Björkman L, et al. Neutrophil signaling that challenges dogmata of $\mathrm{G}$ proteincoupled receptor regulated functions. ACS Pharmacol Transl Sci. 2020 Mar 11;3(2):20320.

4 Arruda MA, Barja-Fidalgo C. NADPH oxidase activity: in the crossroad of neutrophil life and death. Front Biosci. 2009;14:4546-56.

5 Futosi K, Fodor S, Mócsai A. Reprint of neutrophil cell surface receptors and their intracellular signal transduction pathways. Int Immunopharmacol. 2013;17(4):1185-97.

6 Lammermann T, Kastenmuller W. Concepts of GPCR-controlled navigation in the immune system. Immunol Rev. 2019;289(1): 205-31.

7 Holmdahl R, Sareila O, Olsson LM, Bäckdahl L, Wing K. Ncf1 polymorphism reveals oxidative regulation of autoimmune chronic inflammation. Immunol Rev. 2016;269(1):22847.

8 Bylund J, Brown KL, Movitz C, Dahlgren C, Karlsson A. Intracellular generation of superoxide by the phagocyte NADPH oxidase: how, where, and what for? Free Radic Biol Med. 2010;49(12):1834-45.

9 Sundqvist M, Christenson K, Björnsdottir H, Osla V, Karlsson A, Dahlgren C, et al. Elevated mitochondrial reactive oxygen species and cellular redox imbalance in human NADPHoxidase-deficient phagocytes. Front Immunol. 2017;8:1828.

10 Thomas DC. How the phagocyte NADPH oxidase regulates innate immunity. Free Radic Biol Med. 2018;125:44-52.

11 Campbell JJ, Foxman EF, Butcher EC. Chemoattractant receptor cross talk as a regulatory mechanism in leukocyte adhesion and migration. Eur J Immunol. 1997;27(10): 2571-8.

12 Heit B, Tavener S, Raharjo E, Kubes P. An intracellular signaling hierarchy determines direction of migration in opposing chemotactic gradients. J Cell Biol. 2002;159(1):91-102.

13 Kitayama J, Carr MW, Roth SJ, Buccola J, Springer TA. Contrasting responses to multiple chemotactic stimuli in transendothelial migration: heterologous desensitization in neutrophils and augmentation of migration in eosinophils. J Immunol. 1997;158(5): 2340-9.

14 Fu H, Bylund J, Karlsson A, Pellmé S, Dahlgren $\mathrm{C}$. The mechanism for activation of the neutrophil NADPH-oxidase by the peptides formyl-Met-Leu-Phe and Trp-Lys-Tyr-MetVal-Met differs from that for interleukin-8. Immunology. 2004;112(2):201-10.
15 Onnheim K, Christenson K, Gabl M, Burbiel JC, Muller CE, Oprea TI, et al. A novel receptor cross-talk between the ATP receptor P2Y and formyl peptide receptors reactivates desensitized neutrophils to produce superoxide. Exp Cell Res. 2014;323(1):209-17.

16 Forsman H, Önnheim K, Andréasson E, Christenson K, Karlsson A, Bylund J, et al. Reactivation of desensitized formyl peptide receptors by platelet activating factor: a novel receptor cross talk mechanism regulating neutrophil superoxide anion production. PLoS One. 2013;8(3):e60169.

17 Sundqvist M, Karin C, Michael G, André H, Karin J, Thor M, et al. Staphylococcus aureusderived PSMa peptides activate neutrophil FPR2 but lack the ability to mediate $\beta$-arrestin recruitment and chemotaxis. J Immunol. 2019 Dec 15;203(12):3349-60.

18 Wang J, Wu X, Simonavicius N, Tian H, Ling L. Medium-chain fatty acids as ligands for orphan G protein-coupled receptor GPR84. J Biol Chem. 2006;281(45):34457-64.

19 Suzuki M, Takaishi S, Nagasaki M, Onozawa $\mathrm{Y}$, Iino I, Maeda $\mathrm{H}$, et al. Medium-chain fatty acid-sensing receptor, GPR84, is a proinflammatory receptor. J Biol Chem. 2013;288(15): 10684-91.

20 Sundqvist M, Christenson K, Holdfeldt A, Gabl M, Mårtensson J, Björkman L, et al. Similarities and differences between the responses induced in human phagocytes through activation of the medium chain fatty acid receptor GPR84 and the short chain fatty acid receptor FFA2R. Biochim Biophys Acta Mol Cell Res. 2018;1865(5):695-708.

21 Wojciechowicz ML, Ma'ayan A. GPR84: an immune response dial? Nat Rev Drug Discov. 2020;19(6):374.

22 Marsango S, Barki N, Jenkins L, Tobin AB, Milligan G. Therapeutic validation of an orphan $G$ protein-coupled receptor: the case of GPR84. Br J Pharmacol. 2020 Sep 1. Epub ahead of print.

23 Liu Y, Zhang Q, Chen LH, Yang H, Lu W, Xie $\mathrm{X}$, et al. Design and synthesis of 2-alkylpyrimidine-4,6-diol and 6-alkylpyridine-2,4-diol as potent GPR84 agonists. ACS Med Chem Lett. 2016;7(6):579-83.

24 Lucy D, Purvis GSD, Zeboudj L, Chatzopoulou M, Recio C, Bataille CJR, et al. A biased agonist at immunometabolic receptor GPR84 causes distinct functional effects in macrophages. ACS Chem Biol. 2019;14(9):2055-64.

25 Boyum A. Isolation of mononuclear cells and granulocytes from human blood. Isolation of monuclear cells by one centrifugation, and of granulocytes by combining centrifugation and sedimentation at $1 \mathrm{~g}$. Scand J Clin Lab Invest Suppl. 1968;97:77-89.

26 Boyum A. Isolation of lymphocytes, granulocytes and macrophages. Scand J Immunol. 1976;(Suppl 5):9-15.
27 Dahlgren C, Björnsdottir H, Sundqvist M, Christenson K, Bylund J. Measurement of respiratory burst products, released or retained, during activation of professional phagocytes. Methods Mol Biol. 2020;2087:301-24.

28 Zhang Q, Yang H, Li J, Xie X. Discovery and characterization of a novel small-molecule agonist for medium-chain free fatty acid receptor G protein-coupled receptor 84. J Pharmacol Exp Ther. 2016;357(2):337-44.

29 Cannaert A, Storme J, Franz F, Auwärter V, Stove CP. Detection and activity profiling of synthetic cannabinoids and their metabolites with a newly developed bioassay. Anal Chem. 2016;88(23):11476-85.

30 Dahlgren C, Gabl M, Holdfeldt A, Winther $\mathrm{M}$, Forsman H. Basic characteristics of the neutrophil receptors that recognize formylated peptides, a danger-associated molecular pattern generated by bacteria and mitochondria. Biochem Pharmacol. 2016; 114:22-39.

31 Karlsson J, Bylund J, Movitz C, Björkman L, Forsman H, Dahlgren C. A methodological approach to studies of desensitization of the formyl peptide receptor: role of the read out system, reactive oxygen species and the specific agonist used to trigger neutrophils. J Immunol Methods. 2010;352(1-2):45-53.

32 Forsman H, Andréasson E, Karlsson J, Boulay F, Rabiet MJ, Dahlgren C. Structural characterization and inhibitory profile of formyl peptide receptor 2 selective peptides descending from a PIP2-binding domain of gelsolin. J Immunol. 2012;189(2):629-37.

33 Labeguere F, Dupont S, Alvey L, Soulas F, Newsome G, Tirera A, et al. Discovery of 9-cyclopropylethynyl-2-((S)-1-[1,4]dioxan2-ylmethoxy)-6,7-dihydropyrimido[6,1-a] isoquinolin-4-one (GLPG1205), a unique GPR84 negative allosteric modulator undergoing evaluation in a phase II clinical trial. J Med Chem. 2020 Nov 25;63(22):13526-45.

34 Luttrell LM, Wang J, Plouffe B, Smith JS, Yamani L, Kaur $S$, et al. Manifold roles of $\beta$-arrestins in GPCR signaling elucidated with siRNA and CRISPR/Cas9. Sci Signal. 2018; 11(549): eaat7650.

35 Gabl M, Holdfeldt A, Sundqvist M, Lomei J, Dahlgren C, Forsman H. FPR2 signaling without $\beta$-arrestin recruitment alters the functional repertoire of neutrophils. Biochem Pharmacol. 2017;145:114-22.

36 Sundqvist M, Holdfeldt A, Wright SC, Møller TC, Siaw E, Jennbacken K, et al. Barbadin selectively modulates FPR2-mediated neutrophil functions independent of receptor endocytosis. Biochim Biophys Acta Mol Cell Res. 2020;1867(12):118849.

37 Ye RD, Boulay F, Wang JM, Dahlgren C, Gerard $\mathrm{C}$, Parmentier $\mathrm{M}$, et al. International union of basic and clinical pharmacology. LXXIII. Nomenclature for the formyl peptide receptor (FPR) family. Pharmacol Rev. 2009; 61(2):119-61. 
$38 \mathrm{Fu} \mathrm{H}$, Karlsson J, Björkman L, Stenfeldt AL, Karlsson A, Bylund J, et al. Changes in the ratio between FPR and FPRL1 triggered superoxide production in human neutrophils: a tool in analysing receptor specific events. J Immunol Methods. 2008;331(12):50-8.

39 Holdfeldt A, Dahlstrand Rudin A, Gabl M, Rajabkhani Z, König GM, Kostenis E, et al. Reactivation of Gai-coupled formyl peptide receptors is inhibited by Gaq-selective inhibitors when induced by signals generated by the platelet-activating factor receptor. J Leukoc Biol. 2017;102(3):871-80.

40 Forsman H, Winther M, Gabl M, Skovbakke SL, Boulay F, Rabiet MJ, et al. Structural changes of the ligand and of the receptor alters the receptor preference for neutrophil activating peptides starting with a formylmethionyl group. Biochim Biophys Acta. 2015; 1853(1):192-200.

41 Clark RA. Chemotactic factors trigger their own oxidative inactivation by human neutrophils. J Immunol. 1982;129(6):2725-8.

42 Lind S, Dahlgren C, Holmdahl R, Olofsson P, Forsman H. Functional selective FPR1 signaling in favor of an activation of the neutrophil superoxide generating NOX2 complex. J Leukoc Biol. 2020 Oct 11. Epub ahead of print.

43 Forsman H, Salomonsson E, Onnheim K, Karlsson J, Björstad A, Leffler H, et al. The beta-galactoside binding immunomodulatory lectin galectin-3 reverses the desensitized state induced in neutrophils by the chemotactic peptide f-Met-Leu-Phe: role of reactive oxygen species generated by the NADPH-oxidase and inactivation of the agonist. Glycobiology. 2008;18(11):905-12.

44 Tsai YF, Yang SC, Hwang TL. Formyl peptide receptor modulators: a patent review and potential applications for inflammatory diseases (2012-2015). Expert Opin Ther Pat. 2016; 26(10):1-18.

45 Freedman NJ, Lefkowitz RJ. Desensitization of G protein-coupled receptors. Recent Prog Horm Res. 1996;51:319-51; discussion 52-3.

46 Hoffmann MH, Griffiths HR. The dual role of Reactive Oxygen Species in autoimmune and inflammatory diseases: evidence from preclinical models. Free Radic Biol Med. 2018; 125:62-71.

47 Dahlgren C, Karlsson A, Bylund J. Intracellular neutrophil oxidants: from laboratory curiosity to clinical reality. J Immunol. 2019; 202(11):3127-34.

48 van der Weyden L, Speak AO, Swiatkowska A, Clare S, Schejtman A, Santilli G, et al. Pulmonary metastatic colonisation and granulomas in NOX2-deficient mice. J Pathol. 2018; 246(3):300-10.

49 Konaté MM, Antony S, Doroshow JH. Inhibiting the activity of NADPH oxidase in can- cer. Antioxid Redox Signal. 2020;33(6):43554.

50 Raabe CA, Gröper J, Rescher U. Biased perspectives on formyl peptide receptors. Biochim Biophys Acta Mol Cell Res. 2019; 1866(2):305-16.

51 Chen K, Bao Z, Gong W, Tang P, Yoshimura $\mathrm{T}$, Wang JM. Regulation of inflammation by members of the formyl-peptide receptor family. J Autoimmun. 2017;85:64-77.

52 Richardson RM, Ali H, Tomhave ED, Haribabu B, Snyderman R. Cross-desensitization of chemoattractant receptors occurs at multiple levels. Evidence for a role for inhibition of phospholipase C activity. J Biol Chem. 1995;270(46):27829-33.

53 Ali H, Richardson RM, Haribabu B, Snyderman R. Chemoattractant receptor cross-desensitization. J Biol Chem. 1999;274(10):6027-30.

54 Rossi FW, Napolitano F, Pesapane A, Mascolo M, Staibano S, Matucci-Cerinic M, et al. Upregulation of the $\mathrm{N}$-formyl peptide receptors in scleroderma fibroblasts fosters the switch to myofibroblasts. J Immunol. 2015; 194(11):5161-73.

55 Gagnon L, Leduc M, Thibodeau JF, Zhang MZ, Grouix B, Sarra-Bournet F, et al. A newly discovered antifibrotic pathway regulated by two fatty acid receptors: GPR40 and GPR84. Am J Pathol. 2018;188(5): $1132-48$. 